\title{
Assessing agricultural vulnerability to climate change in Sri Lanka
}

\author{
F. Niranjan', N.P.C. Uddika1, M.C.S. Bantilan² and N.P. Singh²
}

\begin{abstract}
Climate change is a global phenomenon having its impact and consequences on environmental changes as well as livelihood adaptations. Vulnerability is defined as the degree to which a system is susceptible to the adverse effects of climate change. The objective of this study was to improve the understanding of the vulnerability to climate change that occurs spatially with time to make investment decisions. Analysis was undertaken for 22 districts in Sri Lanka. Indices were formulated based on those developed by the Inter-Governmental Panel on Climate Change (IPCC) for exposure, sensitivity and adaptive capacity. Identification of the functional relationships between indicators and vulnerability were done. All cross sectional data were collected from secondary sources for a 30-year period from 1977 to 2007. Districts were compared in terms of the vulnerability indices. Chi-squares test was employed to find out associations. Badulla was the most exposed district to climate-related events in 1977 and Nuwara-Eliya was the least. In 2007, Kurunegala was the most exposed district and the least was Matara. In 1977, Colombo was the most sensitive district while Mannar was the least sensitive while in 2007, Gampaha was the most sensitive district and Trincomalee was the least. In terms of the adaptation capacity, Jaffna district had the highest capacity in 1997 and Anuradhapura had the lowest. In 2007, Batticaloa District showed the highest adaptation capacity while Anuradhapura showed the lowest. Colombo as the most vulnerable district in 1977 and it remained the same over a 30year period from 1977 to 2007. Nuwara Eliya and Polonnaruwa had emerged as the least vulnerable districts in 1977 and 2007, respectively. The Chi-square test revealed that the ranking of districts has no concordance with the overall vulnerability. Although the results were not statistically significant, this analysis has provided a sound theoretical base for analyzing vulnerability to climate change. Availability of data for more indicators would have resulted in a more accurate judgment. However, it can be suggested that more attention has to be paid to the most vulnerable areas by launching Government development programmes aiming livelihood and infrastructure improvement. Vulnerability status of the districts must be considered in future policy formulations of the Sri Lankan Government.
\end{abstract}

Keywords: Climate change, vulnerability, exposure, sensitivity, adaptive capacity

\section{Introduction}

Climate change is a global phenomenon and is one of the most important considerations with respect to food security, human health, extinction of flora and fauna, etc. Hence, the need for the construction of proper methods to predict the possible climate related impacts has arisen. This study follows the third assessment report of the Inter-Governmental Panel on Climate Change (IPCC, 2001) in which

\footnotetext{
Sri Lanka Council for Agricultural Research Policy, Colombo, Sri Lanka

2 International Crops Research Institute for the Semi-Arid Tropics, Patancheru, India

* Corresponding author: niranjanfr_03@yahoo.com
} 
vulnerability has been defined as the degree to which a system is susceptible or unable to cope with the adverse effects of climate change, including climate variability and extremes. Vulnerability is a function of the character, magnitude and rate of climate variation to which a system is exposed, as well as the sensitivity and the adaptive capacity of the system (McCarthy et al., 2001).

Exposure can be interpreted as the direct danger and the nature and extent of changes to a region's climate variables (e.g. temperature, precipitation and extreme weather events).Sensitivity describes the human-environmental conditions that can worsen and ameliorate the hazard or trigger an impact. Adaptive capacity represents the potential to implement adaptation measures that helps to avert potential impacts. People in Sri Lanka need to adjust to a climate that is changing and accordingly adapt with layers of resilience in their practices and investment decisions. Therefore, it is important to understand vulnerability to climate change in Sri Lanka that occurs spatially over time. The objective of the study was to improve the understanding of the vulnerability to climate change that occurs spatially with time to make investment decisions.

\section{Materials and Methods}

\section{Data collection}

All the relevant data were collected from secondary sources based on the indicators and were discussed below under each component. Set of indicators was used to select the study area based on (a) Availability of data and (b) Personal judgment of previous research. In this case, previous research conducted on climate change in Sri Lanka (Punyawardena, 2002; De Costa, 2008; De Silva, 2008; Premalal, 2008; 2009) were considered. As vulnerability is dynamic over time, the data for each year for all the indicators in each District were collected for the analysis. However, old data for some indicators were not available. Most of the time, relevant data for the districts in the Northern Province were not available due to non-execution of periodic Government surveys. However, attention was paid to obtain data during available years to be used in place of non-available.

\section{Variables and measurements}

Three components namely, exposure, sensitivity and adaptation capacity were considered in the study. For each component, indices were formulated by considering indicators explained by the IPCC (IPCC, 2001). A vulnerability index (VI) was computed for each period of time for each district for comparison.

Exposure: Data for exposure such as number of floods and droughts events, changes in maximum temperature, minimum temperature and rainfall were obtained from the office records of the Department of Meteorology (DOM, 2010) from 1977 to 2007. 
Sensitivity: Data for sensitivity indicators such as degradation of vegetation (forest area), total rural population $/ \mathrm{km}^{2}$, number of small holdings in agricultural sector, area under major crops and irrigation intensity of paddy for the period 1977-2007 were extracted from various issues of the Statistical Abstracts (DCS, 2010a). In Sri Lanka, paddy is considered as the major food grain and therefore irrigation intensity data were taken based on paddy cultivation. Degradation of vegetation was taken as a proxy for the land degradation index. Two types of forest areas i.e. dense forest and sparse forest, were considered to obtain the total forest area. In Sri Lanka, tea, rubber, coconut and paddy are considered as major economic crops, hence the area under those crops were taken into consideration on an annual basis.

Adaptation capacity: Data for adaptation capacity such as percentage of persons aged 15 years or above who are able to read and write(literacy rate), unemployment rate, amount of paddy produced per ha (food grain production per unit area) were taken from various issues of the Statistical Abstracts published by the DCSSL. Data on number of farmers engaged in agriculture were obtained from various issues of the Labour Force Survey Reports (DCS, 2010b). Data for cropping intensity of paddy was obtained from the survey on agriculture from 1977-2007. Data on number of cows used for milk production was obtained from Livestock Statistics (DCS, 2010C). These indicators were considered as per the IPCC assessment report (IPCC, 2001).

\section{Data analysis}

Construction of vulnerability index $(\mathrm{VI})$ was done by using the method proposed by IPCC (2001). Normalization of indicators was done based on functional relationship between an indicator and vulnerability using the Human Development Index (HDI; UNDP 2006). Kendall's coefficient of concordance (W) and chi-square statistic ( $\left.\mathrm{X}^{2}\right)$ were calculated to compare the test statistics to conclude overall vulnerability in Sri Lanka (Equations 1, 2 and 3).

$$
W=\frac{12 S}{M^{2}\left(M^{3}-M\right)}
$$

(Equation 1)

Where;' $m$ '= the number of components, and ' $M$ '= the number of regions and;

$$
S=\sum_{i=1}^{i=M}\left(R_{i}-\bar{R}\right)^{2}
$$

(Equation 2)

where $\mathrm{Ri}=$ sum of the ranks of regions $\mathrm{I}$ and $\bar{R}=\mathrm{m}(M+1) / 2$. W lies between $\mathrm{o}$ and1. If $W=1$, there is perfect unanimity among the different components in ordering the regions, and id $\mathrm{W}=0$, there is no overall trend of agreement among the components in ranking the regions. The significance of $\mathrm{W}$ was tested using Chi square statistic. 


\section{Results and Discussion}

\section{Exposure}

The district level index of exposure indicated that Badulla (Uva province) was identified as the district with the highest exposure to climate related events and Nuwara Eliya (Central province) was the lowest in 1977 (Figure 1). The highest change in minimum and maximum temperatures, and rainfall with high number of flood and drought events made Badulla to be more selected as the most exposed District to climate change in the year 1977. However, in 2007, Kurunegala became the highest exposed district due to similar reasons explained earlier, with Matara as the lowest. Analysis for the period of 1977 to 2007 indicated that, Anuradhapura district had changed its rank from 5 to 11 , Hambantota district from 13 to 14 and Puttalam district from 7 to 15. The results revealed that the exposure of three districts, which are in the Dry Zone (mainly in the agro-ecological region $\mathrm{DL}_{4}$ ) of Sri Lanka, to climate related events has reduced over time from 1977 to 2007 (Figure 1) mainly due to the lesser changes in minimum and maximum temperature, and relatively less number of flood and drought events.

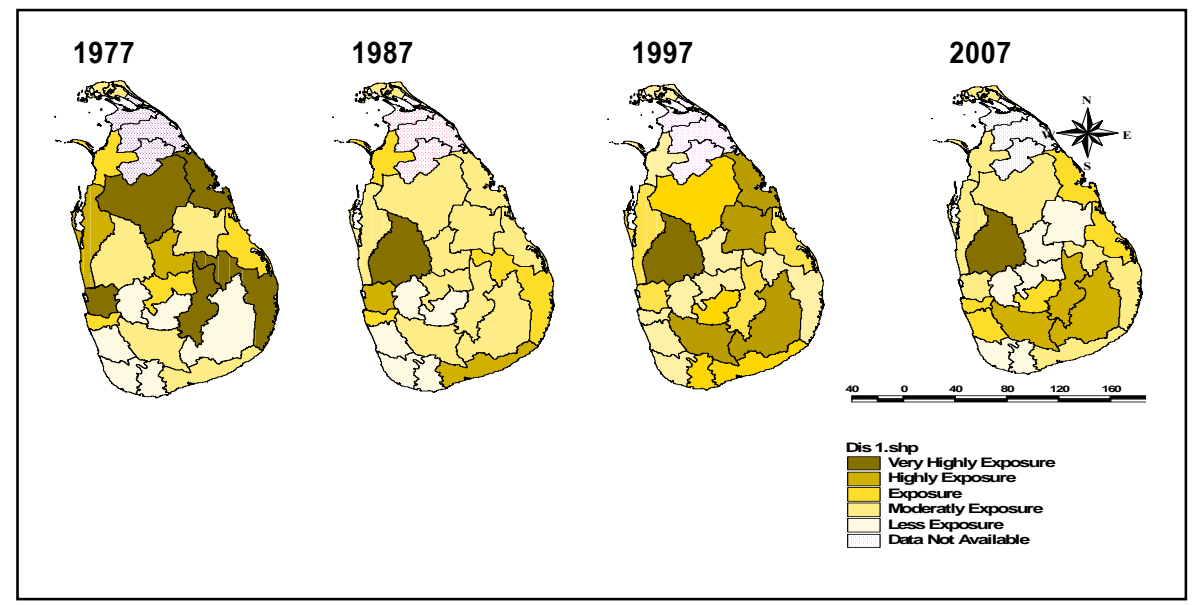

Figure 1. Variation in exposure to climate change in different districts of Sri Lanka (1977-2007)

\section{Sensitivity}

Colombo (Western province) was the district with the highest sensitivity index while Mannar was the lowest in 1997. Gampaha (Western province) was selected as the district with the highest sensitivity to climate related activities and Trincomalee as the least sensitive in 2007 (Figure 2). Compared to districts in the Dry Zone of Sri Lanka, population density and the number of small holdings were relatively high in Colombo and Gampaha districts (in the Wet Zone), which in turn have increased their sensitivity to climate change. Concurrently, degradation of vegetation/forest, area under major crops and irrigation intensity were recorded from these two districts over the study period, resulting relatively in high sensitive status. Anuradhapura and 
Puttalam districts have shown hardly any change in connection with the district ranking for sensitivity to climate change over 30-year period from 1977 to 2007 while Hambantota was ranked $11^{\text {th }}$ in 1977 and $14^{\text {th }}$ in 2007, indicating that the sensitivity of the latter to climate change has reduced over time. This may be due to the newly constructed reservoirs, and relatively less damages to the vegetation despite new development. Properly planned development may be the reason for reduction in sensitivity to climate change in Hambantota over the study period (Figure 2).

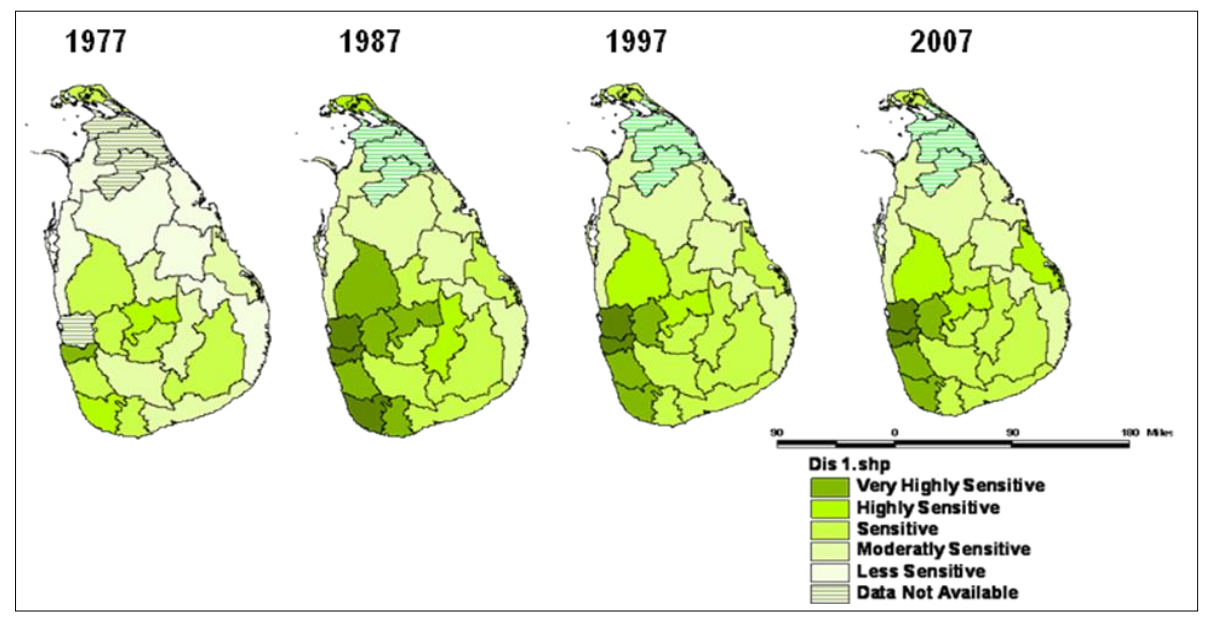

Figure 2. Variation in sensitivity to climate change in different districts of Sri Lanka (1977-2007)

\section{Adaptation capacity}

The Jaffna district (Northern province) showed the highest adaptation capacity over climate change and Anuradhapura district (North Central province) the lowest capacity in 1997 (Figure 3).

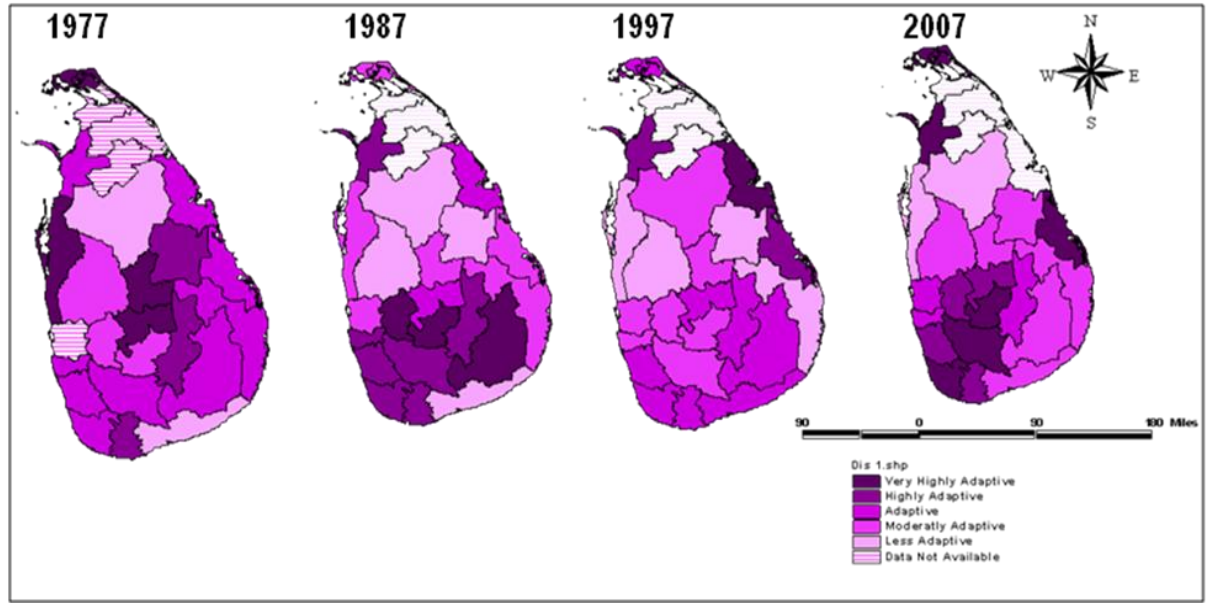

Figure 3. Variation in adaptation capacity to climate change in different districts of Sri Lanka (1977-2007) 
Thirty years later, in 2007, Batticaloa district (Eastern province) showed the highest adaptation capacity while it was the lowest in Anuradhapura district (North Central province). Jaffna and Batticaloa districts has shown relatively higher literacy rate, lower unemployment rate, higher productivity of paddy in terms of land and higher cropping intensity of paddy compared to those of Anuradhapura district thus proving better capacity to implement adaptation measures helping avert potential impacts from climate change. Anuradhapura district showed an inter-change of ranking between 21 and 22 over the period 1977-2007 indicating hardly any change in the adaptation capacity (Figure 3).Hambantota district, too, showed an inter-change of ranking between 20 and 17, indicating relatively less adaptation capacity during the study period 1977-2007.

In the Puttalam district, the adaptation capacity has reduced in drastically way (from and Adaptation Index of 4 in 1977 to 21 in 2007). This could probably be due to the relatively higher unemployment rate, less productivity from paddy, farmers deviating from paddy cultivation, and reducing number of cows in milk production (Figure 3).

\section{Overall vulnerability}

Vulnerability was assessed by considering all three determinants of exposure, sensitivity and adaptive capacity. It was evident that in 1977, Colombo (Western province) was the highest vulnerable district, which remained unchanged upto 2007 (Figure 4).

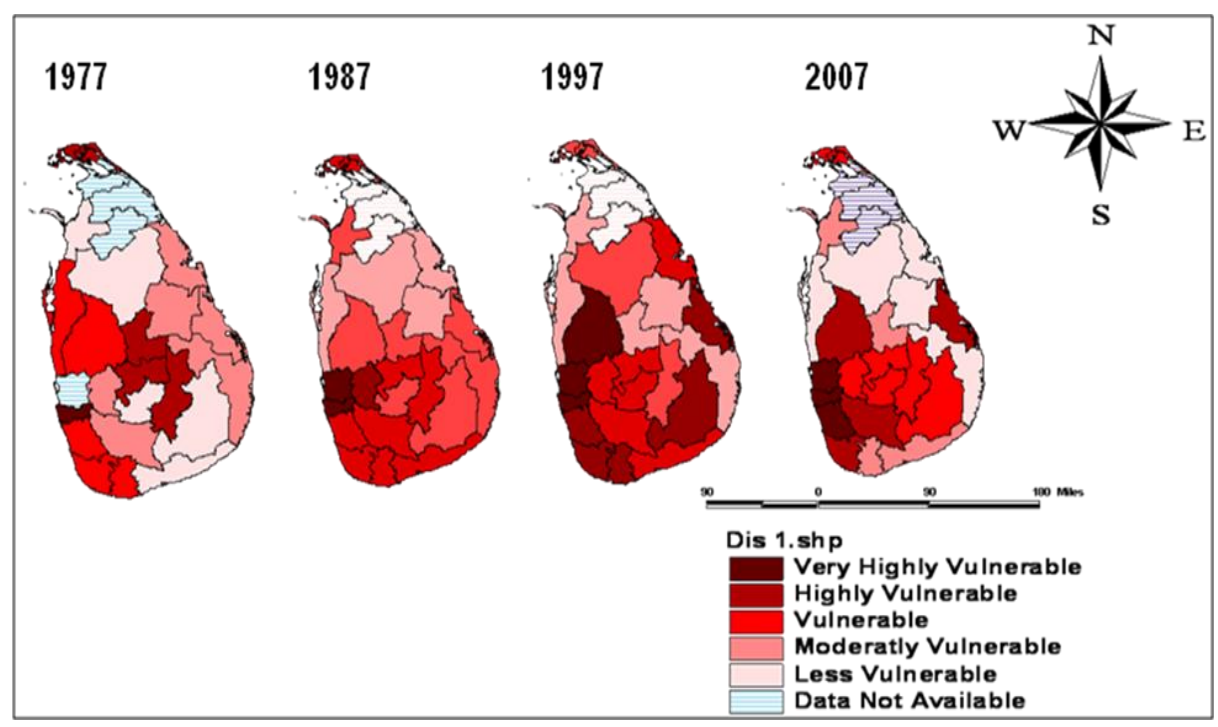

Figure 4. Variation in overall vulnerability to climate change in different districts of Sri Lanka $(1977-2007)$

Nuwara Eliya (Central province) was categorized as the least vulnerable district in 1977 while Polonnaruwa (North Central province) least vulnerable in 2007. 
Vulnerability status in Anuradhapura district (North central province) has reduced over the period from 1977 to 2007 during 10-year intervals. Puttlam district (North Western province) has shown a higher reduction of vulnerability from 1977 to 2007 (Figure 4).

The Kendall's coefficient of concordance and Chi-square test statistic values for result of IPCC were shown in Table 5.

Table 5. The calculated values for Kendall's coefficient of concordance and Chi-square test statistics for overall vulnerability in Sri Lanka

\begin{tabular}{ccccc}
\hline \multicolumn{1}{c}{$\begin{array}{c}\text { Calculated } \\
\text { values }\end{array}$} & 1977 & 1987 & 1997 & 2007 \\
\cline { 2 - 6 } $\mathrm{W}^{*}$ & 0.027 & 0.056 & 0.031 & 0.044 \\
$\chi^{2}$ & 1.9682 & 1.8474 & 2.238 & 2.605 \\
\cline { 2 - 5 } W = Kendall's coefficient of concordance; $\chi^{2}=$ Chi-square test $(\mathrm{p}=0.05)$
\end{tabular}

Kendall's coefficient of concordance values concluded a less trend of agreement or unanimity of components considered for assessing the overall vulnerability ranking in Sri Lanka. The chi-squares values concluded that the ranking of districts has no concordance with the overall vulnerability to climate change in Sri Lanka. Although the results were not statistically significant, this analysis has provided a sound theoretical base for analyzing different sources of vulnerability and for the overall vulnerability ranking for different periods of time in Sri Lanka.

\section{Conclusion}

Limited availability of time series data for some indicators exposure, sensitivity and vulnerability to climate change has shown negative consequences on the overall vulnerability and its significance in this study. However, results revealed that more attention has to be paid to highly vulnerable areas by launching Government development programmes in livelihoods and infrastructure improvement. Furthermore, vulnerability status of administrative districts in Sri Lanka must be considered in future policy formulation by the Government.

\section{References}

De Costa, W.A.J.M. (2008): Impacts of Climate Change on the Long-term Variation in the Water Balance of Different Rainfall Seasons in Selected Locations of Sri Lanka, Department of Crop Science, Faculty of Agriculture, University of Peradeniya. DOM (2009): Office Records from 1977-2007. Department of Meteorology, Colombo DCS (2010a): Statistical Abstract (various issues from 1977-2007). Department of Census and Statistics, Colombo 
DCS (2010b): Sri Lanka Labour Force Survey, Various issues from 1977-2010. Colombo

DCS (2010C): Livestock Statistics, Various issues from 1977-2010 Colombo.

De Silva, C.S. (2008): Climate Change Effects on North East Monsoon and Dry Zone Agriculture in Sri Lanka, Department of Agricultural Engineering, Open University of Sri Lanka, Nawala, Nugegoda, Sri Lanka.

IPCC (2001): Climate Change 2001: Impacts, Adaptation, and Vulnerability. Third Assessment Report of the Inter-governmental Panel on Climate Change

McCarthy J.J., Canziani, O.F., Leary, N.A., Dokken, D.J. and White, K.S. (2001): Climate Change 2001: Impacts, Adoption, and vulnerability. Cambridge University Press, 1032 pp.

Premalal, K.H.M.S. (2008): Scientific Paper presented for the training course for Climate Change Adaptation and Mitigation, Swedish Meteorological and Hydrological Institute, Sweden

Premalal, K.H.M.S. (2009): Systematic Meteorological Observations in the department of Meteorology and Climate Change in Sri Lanka. Paper Presented at the Ministry of Environment, Colombo, Sri Lanka

Punyawardena, B.V.R. (2002) Identification of the Potential of Growing Seasons by the Onset of Seasonal Rains: A Study in the DL1 Region of the North Central Dry Zone. J. Natn. Sci. Foundation Sri Lanka 30(1 \& 2): 13-21.

UNDP (2006): Human development report, United Nations Development Program, Available at: http://hdr.undp.org/hdr2006/statistics/ 